6th International Electronic Conference on Medicinal Chemistry

\title{
Antimicrobial, antioxidant, and GC-MS analysis of hexane extract of the leaves of Solanum erianthum
}

By

Taye Alawode ${ }^{1,2 *}$, Labunmi Lajide ${ }^{2}$, Bodunde Owolabi ${ }^{2}$ and Mary Olaleye ${ }^{3}$

${ }^{1}$ Department of Chemistry, Federal University Otuoke, Nigeria

${ }^{2}$ Department of Chemistry, Federal University of Technology Akure, Nigeria ${ }^{3}$ Department of Biochemistry, Federal University of Technology Akure , Nigeria

*Corresponding email: onatop2003@yahoo.com
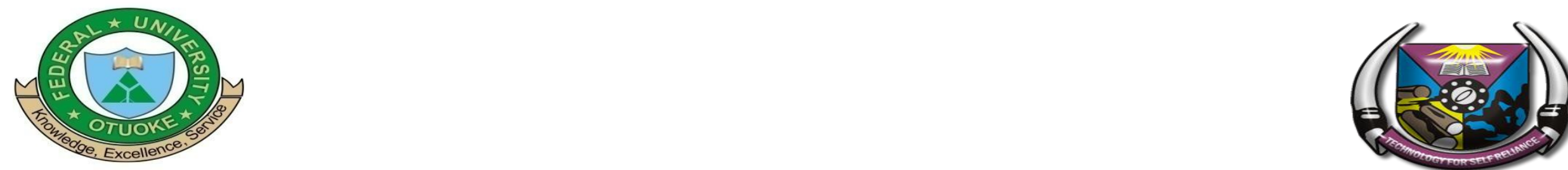


\section{Antimicrobial, Antioxidant and GC-MS Analysis of Hexane Extract of the Leaves of Solanum erianthum}

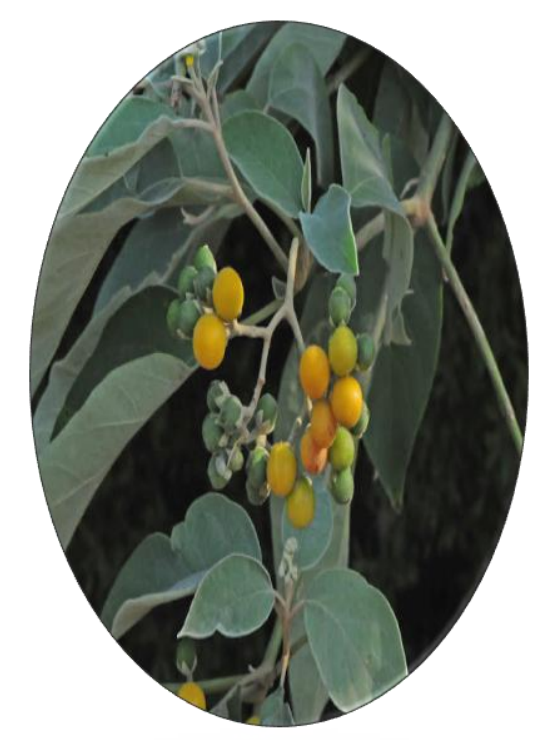

Solanum erianthum

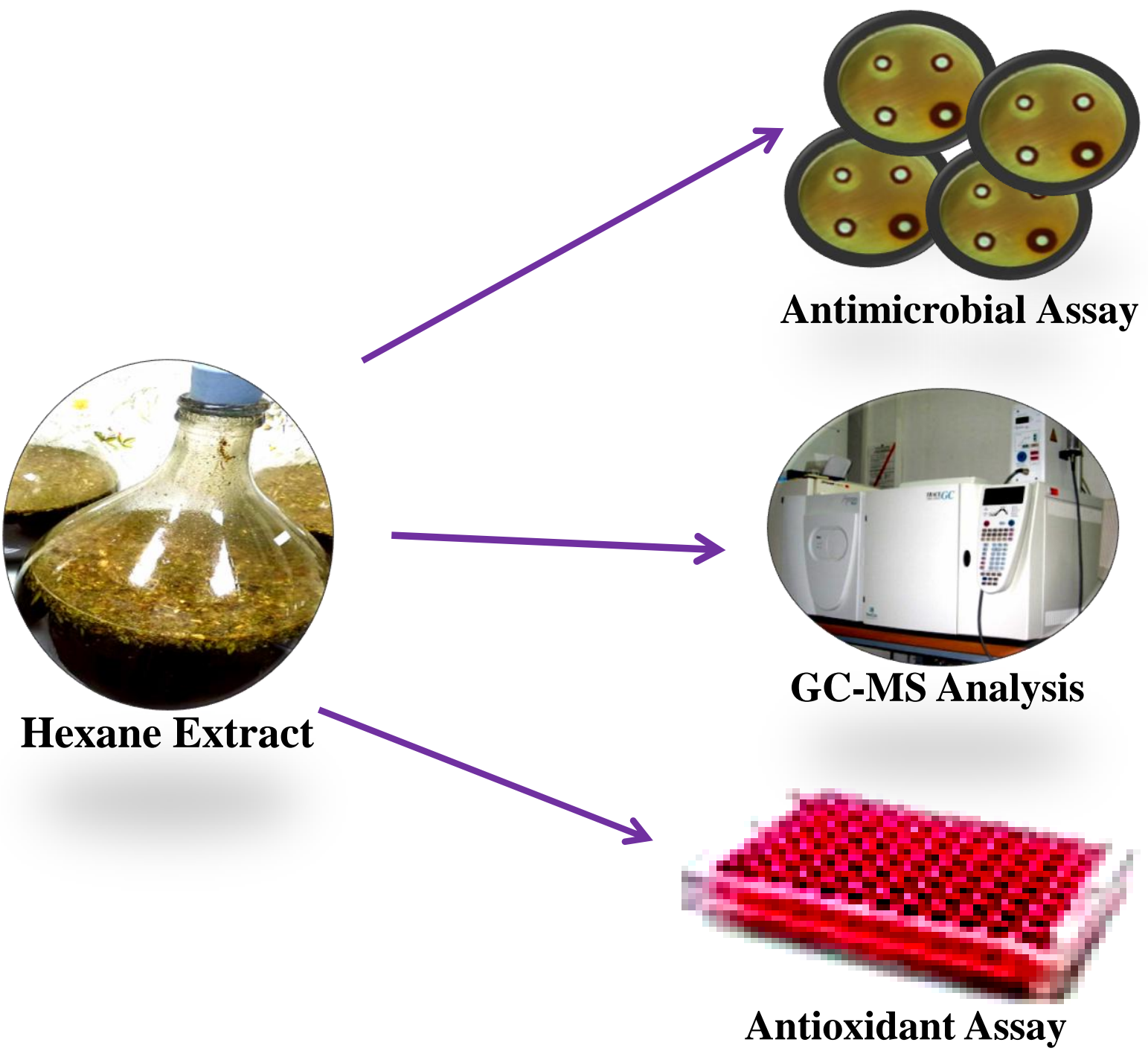




\section{ABSTRACT}

Solanum erianthum is used in ethnomedicine for the treatment of various diseases. In the study, the hexane extract of the plant was screened for antimicrobial and antioxidant activities. Dried leaves samples were extracted with hexane. The extract was screened for activity against Staphylococcus aureus, Escherichia coli, Bacillus subtilis, Pseudomonas aeruginosa, Salmonella typhi, Klebisidlae pneumonae, Candida albicans, Aspergillus niger, Penicillium notatum and Rhizopus stolonifer at concentrations ranging between $6.25 \mathrm{mg} / \mathrm{ml}$ and $200 \mathrm{mg} / \mathrm{ml}$ using the agar diffusion method. The extract was screened for antioxidant activities using the DPPH free radical scavenging assay at concentrations between 0.0625 $\mathrm{mg} / \mathrm{ml}$ and $1 \mathrm{mg} / \mathrm{ml}$. All results were compared with those of the standard drugs. GC-MS analysis of the extract was thereafter carried out. Activities generally increased with the concentration in the antimicrobial assay. The highest zone of inhibition $(28 \mathrm{~mm})$ was obtained against $S$. aureus at $200 \mathrm{mg} / \mathrm{ml}$. The extract, however, did not show a zone of inhibition as high as that of the standard drug (gentamycin and tioconazole) against any of the test organisms. $\mathrm{IC}_{50}$ value of 0.729 was obtained in the DPPH assay which is higher than the $\mathrm{IC}_{50}$ value (of 0.017) got for the standard Ascorbic acid. Some of the major compounds observed in extract include 1-octadecene $(23.59 \%), 9,12$-Octadecadienoic acid (Z,Z) (14.01 $\%)$ and hexadecanoic acid ethyl ester $(8.06 \%)$. These compounds could have contributed to the bioactivities demonstrated by the extract.

Keywords: Solanum erianthum, hexane, antimicrobial, antioxidant, GC-MS 


\section{Introduction}

$\square$ Medicinal plants are widely employed as alternative form of treatment in many countries. Most often, however, the ethnobotanical uses of the plants are not backed up with scientific evidence.

$\square$ Presently, research efforts are often directed at validating these claims. Where the medicinal properties are established, the biologically-active organic molecules responsible for the observed medicinal properties of the plants are isolated in pure form.

$\square$ The present study investigates the leaves of $S$. erianthum for antimicrobial and antioxidant activities. The plant is used for the treatment of skin infections by traditional medical practitioners in south-western Nigeria. 
Phytoconstituents in Hexane Extracts of leaves of S. erianthum

\begin{tabular}{|l|c|}
\hline Tests & Extract \\
\hline Tannins & - \\
\hline Glycosides & - \\
\hline Resin & - \\
\hline Saponins & + \\
\hline Phlobatanins & - \\
\hline Flavonoids & + \\
\hline Sterols & - \\
\hline Phenols & + \\
\hline Carbohydrate & - \\
\hline Alkaloids & + \\
\hline Terpenoids & - \\
\hline
\end{tabular}

Several compounds from these phytochemical groups have been reported to possess antibacterial, antifungal and antioxidant properties

(Othman et al., 2019) 


\section{Results and Discussion (Cont'd)}

\section{Antibacterial activity}

\begin{tabular}{|c|c|c|c|c|c|c|}
\hline \multicolumn{7}{|c|}{ Mean Zone of Inhibition (mm) } \\
\hline $\begin{array}{c}\text { Conc. } \\
(\mathbf{m g} / \mathbf{m l})\end{array}$ & SA & EC & BS & PA & ST & KP \\
\hline 200 & 28 & 26 & 26 & 24 & 20 & 24 \\
\hline 100 & 24 & 22 & 22 & 22 & 18 & 20 \\
\hline 50 & 20 & 18 & 20 & 20 & 16 & 18 \\
\hline 25 & 18 & 14 & 16 & 18 & 14 & 14 \\
\hline 12.5 & 14 & 12 & 14 & 12 & 12 & 12 \\
\hline 6.25 & 10 & 10 & 12 & 10 & 10 & 10 \\
\hline MIC $(\mathrm{mg} / \mathrm{ml})$ & 1.25 & 2.50 & 2.50 & 2.50 & 2.50 & 2.50 \\
\hline $\begin{array}{c}\text { Gentamicin } \\
(10 \mu \mathrm{g} / \mathrm{ml})\end{array}$ & 40 & 40 & 40 & 38 & 40 & 40 \\
\hline
\end{tabular}

SA- S. aureus, EC - E. coli, BS - B. subtilis, PA - P. aeruginosa, ST - S. typhi, $\mathrm{KP}-K$. pneumonia 


\section{Results and Discussion (Cont'd)}

\section{Antifungal activity}

\begin{tabular}{|c|c|c|c|c|}
\hline & \multicolumn{5}{|l|}{ Zone of Inhibition $(\mathbf{m m})$} & \\
\hline $\begin{array}{c}\text { Conc. } \\
(\mathbf{m g} / \mathbf{m l})\end{array}$ & CA & AN & PN & RS \\
\hline 200 & 22 & 20 & 20 & 18 \\
\hline 100 & 20 & 18 & 18 & 16 \\
\hline 50 & 18 & 14 & 16 & 14 \\
\hline 25 & 14 & 12 & 14 & 12 \\
\hline 12.5 & 12 & 10 & 12 & 10 \\
\hline 6.25 & 10 & - & 10 & - \\
\hline MIC $(\mathrm{mg} / \mathrm{ml})$ & 2.50 & 5.00 & 2.50 & 5.00 \\
\hline $\begin{array}{c}\text { Tioconazole }(1 \\
0 \mu \mathrm{g} / \mathrm{ml})\end{array}$ & 26 & 28 & 28 & 28 \\
\hline
\end{tabular}

$\mathrm{CA}-C$. albicans, $\mathrm{AN}-A$. niger, $\mathrm{PN}-P$. notatum, $\mathrm{RS}-R$. stolonifer 


\section{Results and Discussion (Cont'd)}

- Generally, it can be observed that the zones of inhibition increased with increasing concentrations of the extracts. This is in agreement with previous reports (Homaida et al., 2019).

- $S$. aureus is most susceptible to the extract with MIC value of $1.25 \mathrm{mg} / \mathrm{ml}$

- Escherichia coli, Klebsiella pneumoniae and Staphylococcus aureus are gram negative bacteria. Gram-negative bacteria which are known for their ability to restrict the diffusion of hydrophobic compounds through their membranes. Antifungal resistance by $C$. albicans has also been reported to occur with long-term antifungal use and with recurrent infections (Arendrup and Patterson, 2017). 


\section{Results and Discussion (Cont'd)}

The antimicrobial activity observed against the test organisms could be due to the interactions of the plant active metabolites with the organism's cytoplasmic membrane leading to the leakage of intracellular components and precipitation of cytoplasmic contents (Thangamani et al., 2016). 


\section{Results and Discussion (Cont'd)}

\section{DPPH Scavenging Activity: Standard versus Extract}
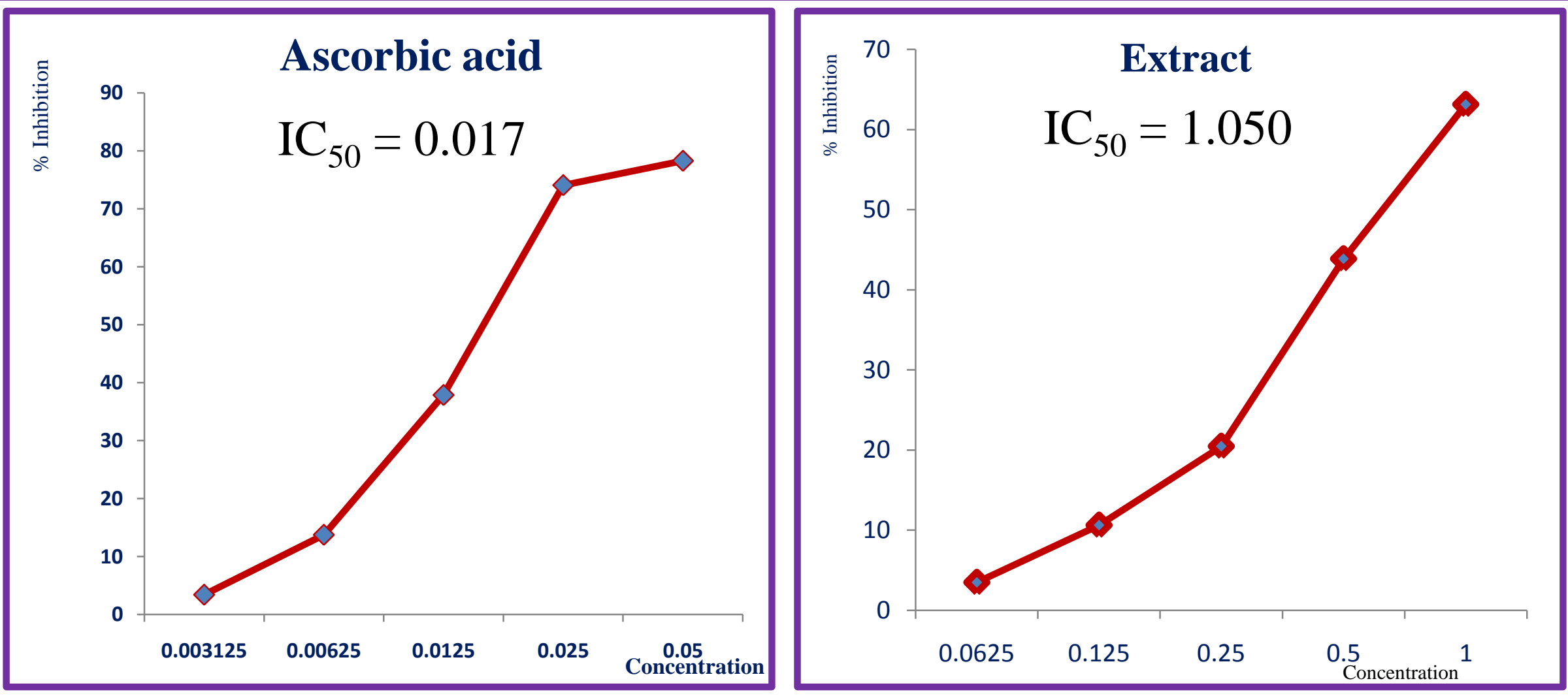

$\checkmark$ The DPPH scavenging properties increased with the concentration of the extracts. Similar trends have been observed in previous studies (Pavithra and Vadivukkarasi, 2015). 


\section{Results and Discussion (Cont'd)}

GC-MS Analysis: Some Compounds detected in the hexane extract of the leaves

$\mathrm{t}_{\mathrm{R}}$ (min.) Area (\%) Name of Compound Quality (\%)

\begin{tabular}{llll}
\hline 11.816 & 1.35 & Butylated Hydroxytoluene & 98 \\
14.162 & 1.23 & Heptadecane & 95 \\
15.318 & 1.34 & Octadecane & 93 \\
15.409 & 1.19 & Hexadecane,1,1'-oxybis & 81 \\
15.787 & 2.28 & $\begin{array}{l}\text { Cyclotetradecane, 1,7, 11-trimethyl-4- } \\
\text { (1-methylethyl)- }\end{array}$ \\
& & Hexadecanoic acid, ethyl ester & 91 \\
17.401 & 8.06 & Ethanol, 2-(Octadecyloxy)- & 93 \\
17.876 & 1.71 & Eicosane & 95 \\
18.551 & 2.33 & 1-Docosene & 90 \\
18.608 & 0.58 & $9,12-$ Octadecadienoic acid (Z,Z) & 96 \\
19.060 & 14.01 & Cyclohexene, 4-(4-ethylcyclohexyl)- & 95 \\
19.123 & 8.54 & 1-pentyl &
\end{tabular}




\section{Results and Discussion (Cont'd)}

\section{Biological activities of some of the detected compounds (Cont'd)}

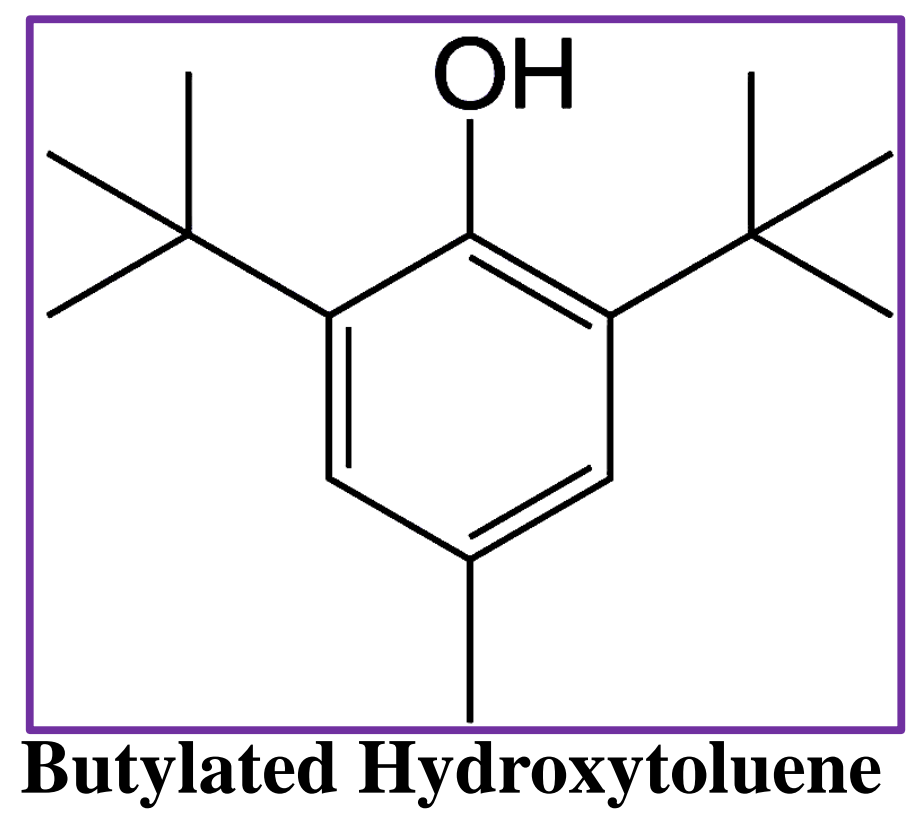

-Butylated hydroxytoluene (BHT) is a most commonly used antioxidant recognized as safe for use in foods containing fats, pharmaceuticals, petroleum products, rubber and oil industries (Yehye et al., 2015). 


\section{Results and Discussion (Cont'd)}

\section{Biological activities of some of the detected compounds (Cont'd)}

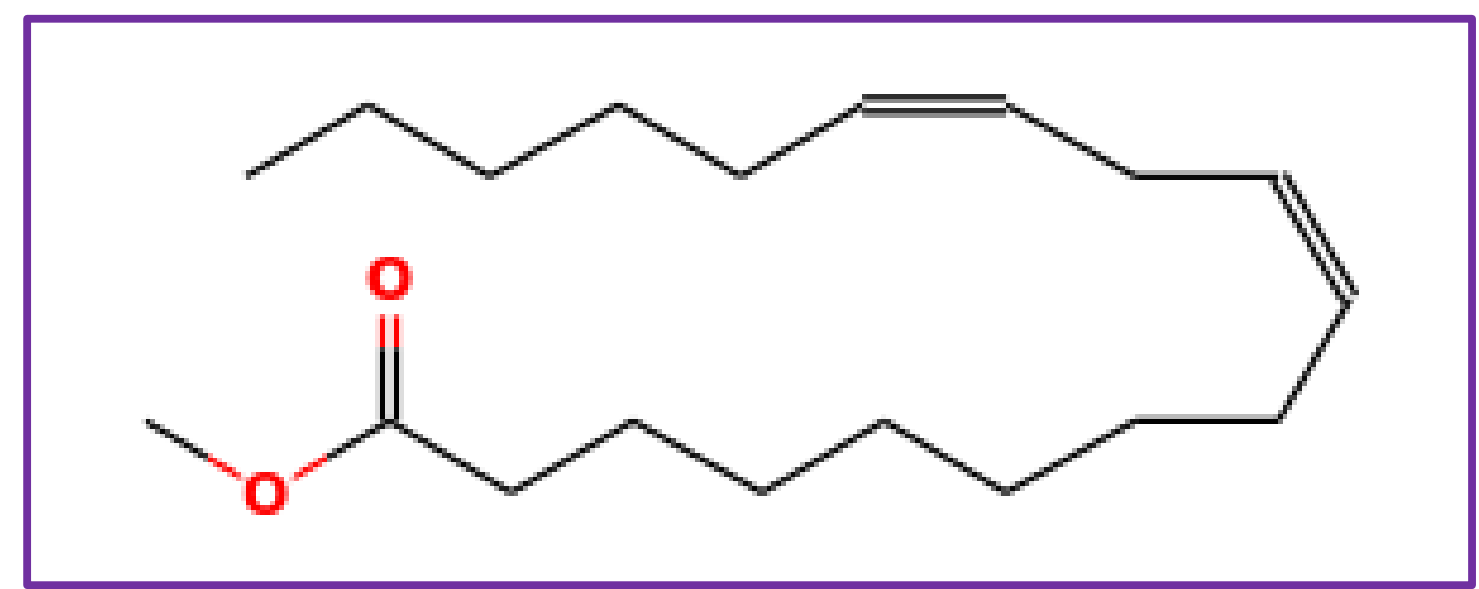

9,12-Octadecadienoic acid (Z,Z)

Antiinflammatory,

hypocholesterolemic,

cancer preventive, hepatoprotective, nematicide, insectifuge(cide), anti histaminic, antieczemic, antiacne, $5-\alpha$ reductase inhibitor, antiandrogenic, antiarthritic, anti coronary, antimicrobial (Adeoye-Isijola et al., 2018). 


\section{Results and Discussion (Cont'd)}

\section{Biological activities of some of the detected compounds (Cont'd)}

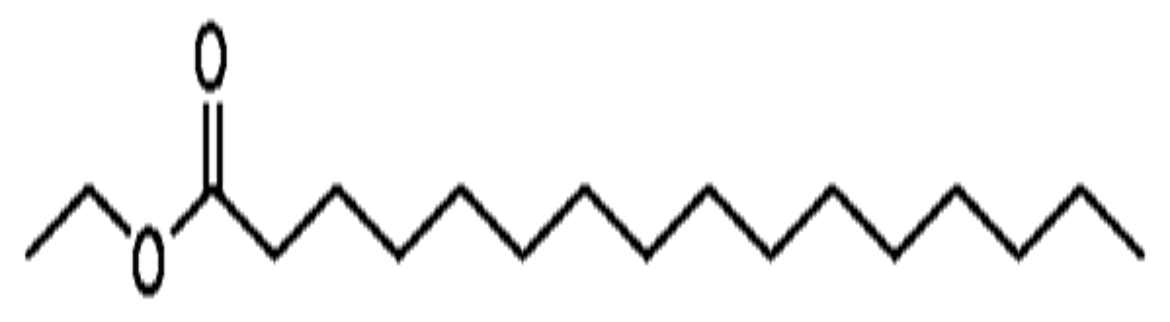
Antioxidant, Hemolytic, Hyp ocholesterolemic, Nematicide (Tyagi and Agarwal, 2017)

Hexadecanoic acid, ethyl ester 


\section{Conclusion}

The hexane extract of the leaves of $S$. erianthum demonstrated antimicrobial and antioxidant activities. While the activities obtained is not as high as those of the standard drugs, the extract has shown some potential as a source of antimicrobial and antioxidant compounds. 